\title{
The burden of different pathogens in acute diarrhoeal episodes among a cohort of Egyptian children less than five years old
}

\author{
Mortada El-Shabrawi ${ }^{1}$, Mohammed Salem ${ }^{1}$, Maha Abou-Zekri' ${ }^{1}$, Suzan El-Naghi², Fetouh Hassanin ${ }^{3}$, \\ Tarek El-Adly ${ }^{1}$, Ayman El-Shamy² \\ ${ }^{1}$ Department of Pediatrics, Cairo University, Cairo, Egypt \\ ${ }^{2}$ National Hepatology and Tropical Medicine Research Institute, Cairo, Egypt \\ ${ }^{3}$ Department of Clinical Pharmacy, Misr International University, Cairo, Egypt
}

Prz Gastroenterol 2015; 10 (3): 173-180 DOI: $10.5114 /$ pg.2015.51186

Key words: diarrhoea, acute, children, Egypt, rotavirus.

Address for correspondence: Dr. Tarek Zakaria El-Adly MD, Cairo University Children's Hospital, Cairo University, 72 El-Thawra St, Heliopolis, Cairo 11341, Egypt, phone: +20 1001100 364, +202 22900 364, e-mail: doctortarek@hotmail.com

\begin{abstract}
Introduction: Diarrhoea continues to cause significant morbidity in Egypt.

Aim: To determine the frequency and distribution of different enteropathogens in acute diarrhoeal episodes, utilising an expanded testing regimen, and to correlate clinical signs and symptoms associated with the detected pathogens.

Material and methods: The case-control study enrolled 356 patients $<5$ years old with acute diarrhoea and 356 age and sexmatched healthy controls. Both cases and controls underwent a full history and physical examination, and provided two rectal swab specimens and a stool sample. Laboratory analysis included stool culture, microscopy, and indirect methods.

Results: Rotavirus was detected in $11 \%$ of patients. Enterotoxigenic Escherichia coli (ETEC), Campylobacter, Shigella, and Salmonella were detected in $7 \%, 3.7 \%, 1.1 \%$, and $1.4 \%$ of patients, respectively; and in $11.1 \%, 3.1 \%, 0.6 \%$, and $0.6 \%$ of controls, respectively, with no significant statistical difference. Cryptosporidium was detected in 3.9\% of cases. Mixed infection was detected in $5.9 \%$ of cases and $0.9 \%$ of controls, with a significant difference $(p<0.001)$. No pathogen was detected in $66.3 \%$ of cases and in $83.5 \%$ of controls. Rotavirus infection was associated with recurrent vomiting, dehydration, and hospitalisation. Bacterial diarrhoea was associated with vomiting (52\%) in ETEC infections, fever (80\%) in Salmonella infections, mucus (100\%) and blood (50\%) in stools of Shigella infections, and convulsions (15\%) in Campylobacter infections.

Conclusions: Rotavirus is a prominent cause of diarrhoea among Egyptian children. Despite utilising an expanded testing regimen, more work is still needed for identification of other enteropathogens that constitute other causative agents of diarrhoea.
\end{abstract}

\section{Introduction}

Diarrhoea is a leading cause of childhood morbidity and mortality in developing countries, and an important cause of malnutrition. Worldwide, children younger than 5 years of age experience an estimated 1.4 billion episodes of diarrhoea each year, leading to 123 million clinic visits, 9 million hospitalisations, and 1.87 million deaths, of which $98 \%$ occur in the developing world [1]. Most deaths are caused by a failure to correct acute dehydration, electrolyte imbalance, and/or nutritional deficits [2]. Identification of the enteropathogens causing diarrhoea is essential to guide the development of vaccines for diarrhoea control.

\section{Aim}

The aim of this study was to determine the frequency and distribution of diarrhoeal pathogens in the faeces of diarrhoeagenic and healthy Egyptian children at a single centre, utilising an expanded testing regimen, and to evaluate the clinical symptoms, signs, and epidemiologic factors suggestive of infection with a detected particular pathogen in this population.

\section{Material and methods}

We conducted the study at the Centre for Social and Preventive Medicine (CSPM) affiliated to the adjacent tertiary referral centre at Cairo University Chil- 
dren's Hospital and regarded as a primary health care centre for the local catchment area. Both walk-in and referred patients $<5$ years of age seeking treatment at the CSPM for a primary complaint of acute diarrhoea without other associated severe illness (e.g. pneumonia) were eligible for the study. Eligible controls had no history of acute diarrhoeal disease within the preceding 30 days and did not present with fever. Controls were identified and enrolled within $48 \mathrm{~h}$ of each matched patient.

The parents of eligible children were consented. The study was ethically approved by the Institutional Review Board (IRB) of the Faculty of Medicine, Cairo University. Stool patterns were described by the median number of stools in the $24 \mathrm{~h}$ before evaluation and median maximal stools on any day since the illness began. Acute diarrhoea was defined as an episode lasting less than 14 days, with 3 or more loose or liquid stools in a 24-hour period or two loose or liquid stools in a 24-hour period, plus one or more other associated symptom/s, including fever (rectal temperature $\geq 38.7^{\circ} \mathrm{C}$ ), dysentery (defined as an illness lasting less than 14 days with visible blood in stools), and history of other diarrhoea-associated signs or symptoms, e.g. abdominal pain or cramps, nausea, vomiting and fever, or dysentery temporally related to the diarrhoeal episode. It was termed acute, watery diarrhoea if there was no visible blood in the stools.

A clinical examination and a questionnaire regarding symptomatology and co-morbid conditions were completed for all cases. The questionnaire for cases included full history of present illnesses including: onset and duration of diarrhoea, number of loose or liquid stools, symptoms of dehydration, nutritional status, associated vomiting, fever, convulsions (defined as a sudden, violent, involuntary contraction of a muscle group), rectal prolapse, mucus and/or blood in stools, and any treatment received or actions taken. Clinical examination was directed specifically to signs of dehydration from the child's general appearance (i.e. eyes, mouth, tongue, skin turgor, anterior fontanel, and radial pulse) and any congenital or chronic conditions. Actions taken and treatment received included oral rehydration solution (ORS), intravenous fluids, or hospital admission. A separate questionnaire was completed for controls, including the epidemiological characteristics, breastfeeding status, as well as the illness associated with their presentation.

\section{Laboratory procedures}

One rectal swab collected from patients and controls was placed in Cary-Blair transport medium (CB), and the second was placed in buffered-glycerol-saline (BGS) enrichment medium. Both inoculated tubes were refrig- erated at $2-8^{\circ} \mathrm{C}$ until processed by the laboratory. Stools collected from cases and selected controls were split into seven aliquots and frozen at $-20^{\circ} \mathrm{C}$. Stool samples could not be collected from all controls. All specimens were transported, within three days of collection, to the laboratory of the United States Naval Medical Research Unit 3 (NAMRU 3) in Abbasia, Cairo, Egypt. During transportation, rectal swabs were placed in a cold box with ice packs, while frozen specimens were placed in a container with dry ice. Upon arrival at NAMRU 3, all specimens were accessioned and rectal swabs were further processed by the Diarrhoeal Disease Laboratory for culture and pathogen identification. Frozen samples were transferred to $\mathrm{a}-70^{\circ} \mathrm{C}$ freezer.

\section{Examination and culture for standard bacterial pathogens}

Rectal swabs were tested for Campylobacter spp., Salmonella spp., and Shigella spp. using routine bacteriological techniques. Faecal swabs were streaked on MacConkey, Shigella-Salmonella, Skirrow's, and thiosulfate-citrate-bile-sucrose (TCBS) agar plates and incubated at $37^{\circ} \mathrm{C}$ for 16 to $24 \mathrm{~h}$. Samples inoculated onto Skirrow's medium were placed in a candle jar and incubated at $42^{\circ} \mathrm{C}$ for $24-48 \mathrm{~h}$. Presumptive identification of non-lactose fermenting bacteria was performed using the four-tube motility, indole, and ornithine [3] differentials; urease; lysine iron agar (LIA) and Kliger's iron agar (KIA). Identification and speciation of thermotolerant Campylobacter spp. (C. coli and C. jejuni) was performed by Gram-stain, oxidase, and hippurate hydrolysis.

Additionally, from the MacConkey agar plate, 5 E. coli-like colonies were picked and tested for expression of heat-labile enterotoxin (LT) and heat-stable enterotoxin (ST) using a GM1-enzyme-linked immunosorbent assay (ELISA) [4, 5]. Colonies producing toxin were further tested for colonisation factor (CF) antigens by monoclonal immuno-dot blot assay [6].

\section{Viral and parasitic pathogen detection}

Frozen stool samples were tested for the presence of rotavirus [7] and Cryptosporidium using commercial ELISA kits, Premier ${ }^{\text {TM }}$ Rotaclone (Premier Rotaclone $\mathrm{R}$, Meridian Bioscience, Cincinnati, $\mathrm{OH}$ ) and Techlab (Techlab, Blacksburg, VA, USA), respectively, according to the manufacturer's instructions. Formalin preserved stool aliquots were also examined with basic microscopy utilising acid-fast staining to provide a comparison analysis for Cryptosporidium parvum and Entamoeba histolytica with the ELISA results.

If an organism was identified from the stool sample, the child was classified as being infected with that organism. If a single pathogen was isolated from 
the stool, then the episode was referred to as pathogen-associated diarrhoea (e.g. enterotoxigenic E. coli (ETEC)-associated diarrhoea). Undiagnosed or pathogen-negative diarrhoea included any episode in which none of the studied pathogens were detected. Any combination of at least two pathogens detected was considered as mixed infection.

\section{Statistical analysis}

Demographic, clinical, and microbiological data were entered and verified using Microsoft access 2007 (Microsoft Inc., Redmond, WA). Statistical analysis was performed with SAS software (version 9.1, SAS Institute Inc., Cary, NC). Percentage distribution was used to describe different variables, median and interquartile range (IQR) were calculated for continuous variables, and $\chi^{2}$ or Fisher's exact $t$-test were used to test for a significant difference in pathogens detected among cases and controls depending on standard assumptions being met. Results were considered significant if the $p$-value was $<0.05$.

\section{Results}

Between September 2007 and September 2009 we enrolled 356 children under 5 years of age with acute diarrhoea from patients attending the CSPM. Another 356 children were enrolled as controls. Forty-five percent of cases were less than 6 months of age (Table I). Regarding the different clinical presentations of the patients (Table II), vomiting was associated in more than half of the cases, fever in $71 \%$, convulsions in $3 \%$, and rectal prolapse in $2 \%$. Mucus-containing stools were noticed by the mother in $6 \%$ of the cases and bloody stools in 20\%. Breastfeeding (Table I) was exclusive in $16 \%$ of cases and not exclusive in $53 \%$, while $31 \%$ were not currently breastfed. Non-exclusively breastfed children outnumbered the other two breastfeeding groups for nearly every pathogen (except for Salmonella and Shigella), as well as for culture-negative diarrhoea cases (Table III).

Of the 356 cases enrolled in this study (Table IV), no pathogen could be identified in 236 (66.3\%) cases. Rotavirus was the most common organism detected in $10.7 \%$ of cases followed by ETEC in 7\%, whereas Campylobacter spp. and Cryptosporidium spp. were detected in $3.7 \%$ and $3.9 \%$ of cases, respectively. Enterotoxigenic $E$. coli was the most common organism detected in controls (11.1\%). Mixed infection was detected in both groups, with a significant statistical difference between cases and controls $(5.9 \%$ and $0.9 \%$, respectively, $p<0.001)$. Rotavirus was the commonest pathogen causing acute diarrhoea below the age of 1 year, followed by ETEC (Table III). Eighty-four percent of cases
Table I. Demographic characteristics of cases $(n=356)$

\begin{tabular}{lc} 
Characteristics & Results, $n$ (\%) \\
\hline Age [months]: & $160(45)$ \\
\hline$\leq 6$ & $105(29)$ \\
\hline $7-12$ & $66(19)$ \\
\hline $13-24$ & $25(7)$ \\
\hline$\geq 25$ & $7(3,13)$ \\
\hline Median (IQR)* & $203(57)$ \\
\hline Mander: & $153(43)$ \\
\hline Female & $215(60)$ \\
\hline Season: & $141(40)$ \\
\hline Warm (May-October) & \\
\hline Cold (November-April) & $56(16)$ \\
\hline Breastfeeding status: & $188(53)$ \\
\hline Exclusive & $112(31)$
\end{tabular}

$I Q R$ - Interquartile range. * Lower and upper quartiles.

Table II. Clinical characteristics of cases $(n=356)$

\begin{tabular}{lc} 
Characteristics & Results \\
\hline Duration of diarrhoea, median (IQR)* [days] & $4(3,7)$ \\
\hline $\begin{array}{l}\text { No. of loose/liquid stools during the last 24 h, } \\
\text { median (IQR)* }\end{array}$ & $8(6,10)$ \\
\hline $\begin{array}{l}\text { Maximum no. of loose/liquid stools on any day, } \\
\text { median (IQR)* }\end{array}$ & $4(3,6)$ \\
\hline \begin{tabular}{l} 
Vomiting, $n(\%)$ \\
\hline Maximum no. of vomiting episodes on any day,
\end{tabular} & $186(52)$ \\
\hline median (IQR) & $4(3,6)$ \\
\hline Fever, $n$ (\%) & $253(71)$ \\
\hline Convulsions, $n(\%)$ & $11(3)$ \\
\hline Rectal prolapse, $n(\%)$ & $6(2)$ \\
\hline Mucus in stools, $n(\%)$ & $69(20)$ \\
\hline Blood in stools, $n(\%)$ &
\end{tabular}

$I Q R$ - Interquartile range, no - number. *Lower and upper quartiles.

of rotavirus were in infants younger than 12 months of age, and all cases of rotavirus were in children younger than 2 years of age. Also, $96 \%$ of cases of ETEC were detected in children younger than 2 years old (Table III). Enterotoxigenic E. coli-associated diarrhoea was accompanied by fever (68\%), vomiting (52\%), and convulsions (4\%), while mucus and blood in stools were present in $72 \%$ and $20 \%$ of cases, respectively (Table V). All pathogens, except Shigella spp., were isolated more often 
Table III. Demographic characteristics of patients according to each pathogen

\begin{tabular}{|c|c|c|c|c|c|c|c|c|}
\hline Characteristics & $\begin{array}{c}\text { Negative* }^{*} \\
N=236 \\
n(\%)\end{array}$ & $\begin{array}{c}\text { Campy } \\
N=13 \\
n(\%)\end{array}$ & $\begin{array}{c}\text { ETEC } \\
N=25 \\
n(\%)\end{array}$ & $\begin{array}{c}\text { Shigella } \\
N=4 \\
n(\%)\end{array}$ & $\begin{array}{c}\text { Crypto } \\
N=14 \\
n(\%)\end{array}$ & $\begin{array}{c}\text { Salmonella } \\
\begin{array}{c}N=5 \\
n(\%)\end{array}\end{array}$ & $\begin{array}{c}\text { Rotavirus } \\
N=38 \\
n(\%)\end{array}$ & $\begin{array}{c}\text { Mixed }^{\dagger} \\
N=21 \\
n(\%)\end{array}$ \\
\hline \multicolumn{9}{|l|}{ Age [months]: } \\
\hline$\leq 6$ & $108(46)$ & $7(54)$ & $11(44)$ & $3(75)$ & $6(43)$ & $3(60)$ & $19(50)$ & $3(14)$ \\
\hline $7-12$ & $66(28)$ & $2(15)$ & $5(20)$ & $0(0)$ & $6(43)$ & $1(20)$ & $13(34)$ & $12(57)$ \\
\hline $13-24$ & $41(17)$ & $4(31)$ & $8(32)$ & $0(0)$ & $2(14)$ & $1(20)$ & $6(16)$ & $4(19)$ \\
\hline$\geq 25$ & $21(9)$ & $0(0)$ & $1(4)$ & $1(25)$ & $0(0)$ & $0(0)$ & $0(0)$ & $2(10)$ \\
\hline \multicolumn{9}{|l|}{ Gender: } \\
\hline Male & $130(55)$ & $8(62)$ & $14(56)$ & $1(25)$ & $8(57)$ & $3(60)$ & $27(71)$ & $12(57)$ \\
\hline Female & $106(45)$ & $5(38)$ & $11(44)$ & $3(75)$ & $6(43)$ & $2(40)$ & $11(29)$ & $9(43)$ \\
\hline \multicolumn{9}{|l|}{ Season: } \\
\hline Warm (May-Oct.) & $137(58)$ & $8(62)$ & $19(76)$ & $2(50)$ & $12(86)$ & $3(60)$ & $23(61)$ & $11(52)$ \\
\hline Cold (Nov.-April) & $99(42)$ & $5(38)$ & $6(24)$ & $2(50)$ & $2(14)$ & $2(40)$ & $15(39)$ & $10(48)$ \\
\hline \multicolumn{9}{|l|}{ Breastfeeding status: } \\
\hline Exclusive & $41(17)$ & $2(15)$ & $6(24)$ & $0(0)$ & $1(7)$ & $1(20)$ & $4(10.5)$ & $1(5)$ \\
\hline Non-exclusive & $123(52)$ & $8(62)$ & $12(48)$ & $2(50)$ & $8(57)$ & $1(20)$ & $23(60.5)$ & $11(52)$ \\
\hline Not currently & $72(31)$ & $3(23)$ & $7(28)$ & $2(50)$ & $5(36)$ & $3(60)$ & $11(29)$ & $9(43)$ \\
\hline
\end{tabular}

Campy - Campylobacter, Crypto-Cryptosporidium, ETEC - enterotoxigenic Escherichia coli. *Negative cases or controls are episodes not associated with studied bacterial agents, rotavirus, or Cryptosporidium. ${ }^{\dagger}$ Any combination of at least two pathogens detected.

Table IV. Distribution of pathogens detected in cases and controls

\begin{tabular}{|c|c|c|c|}
\hline \multirow[t]{2}{*}{ Characteristics } & $\begin{array}{c}\text { Cases } \\
(N=356)\end{array}$ & $\begin{array}{l}\text { Controls } \\
(N=351)\end{array}$ & \multirow[t]{2}{*}{$\begin{array}{c}\text { Value } \\
\text { of } p\end{array}$} \\
\hline & $n(\%)$ & $n(\%)$ & \\
\hline \multicolumn{4}{|l|}{ Sole pathogens: } \\
\hline Campylobacter & $13(3.7)$ & $11(3.1)$ & 0.7 \\
\hline ETEC & $25(7)$ & $39(11.1)$ & 0.06 \\
\hline Shigella & $4(1.1)$ & $2(0.6)$ & 0.7 \\
\hline Cryptosporidium & $14(3.9)$ & $1(0.3)^{\ddagger}$ & $<0.001$ \\
\hline Salmonella & $5(1.4)$ & $2(0.6)$ & 0.5 \\
\hline Rotavirus & $38(10.7)$ & $0(0)^{\ddagger}$ & $\mathrm{N} / \mathrm{A}$ \\
\hline Mixed infection* & $21(5.9)$ & $3(0.9)$ & $<0.001$ \\
\hline Negative $^{\dagger}$ & $236(66.3)$ & $293(83.5)^{\ddagger}$ & $<0.0001$ \\
\hline
\end{tabular}

ETEC - enterotoxigenic Escherichia coli, NA - non-applicable. *Any combination of at least two pathogens detected. ${ }^{\dagger}$ Negative cases or controls are episodes not associated with studied bacterial agents, rotavirus, or Cryptosporidium. ${ }^{*}$ We could not collect stool samples from all controls (as they were diarrhoeafree); accordingly, we could not test for rotavirus or Cryptosporidium as these required stool samples rather than rectal swab for analysis.

among males and were more predominant during the warm seasons (Table III).

Rotavirus-associated diarrhoea cases (Table V) were found to have the highest percentage of fever (89\%), the highest percentage of vomiting (76\%), the highest median for maximum number of vomiting episodes on any day [6], and the highest percentage of rectal prolapse (5\%), when compared with other pathogens and culture-negative cases. Campylobacter-associated diarrhoea cases (Table $V$ ) had the highest percentage of convulsions (15\%) although less than half of the cases experienced fever. The longest duration of diarrhoea (8 days) was seen in Shigella-associated diarrhoea cases, with the highest percentage of mucus (100\%) and blood (50\%) in stools and the smallest percentage of vomiting ( $25 \%$, Table V).

During the 4 days prior to enrolment over one third (35\%) of the cases received antibiotics and over a fifth (22\%) of the cases received oral rehydration solution (ORS). Oral rehydration solution packets to be administered at home were given to $81 \%$ of the cases, whereas intravenous fluids were confined to $4 \%$ only, and hospital admission to 3\%. The reasons for hospitalisation were primarily dehydration, malnutrition, or bloody diarrhoea. A high percentage (84\%) received non-specific medications to treat diarrhoea. Rotavirus-associated diarrhoea cases constituted the highest percentage of cases necessitating intravenous fluids and hospital admission (18\% and 11\%, respectively, Table VI).

\section{Discussion}

Our results showed that $33.7 \%$ of cases were infected with enteropathogens. Bacterial pathogens and 
Table V. Clinical characteristics of cases according to each pathogen

\begin{tabular}{|c|c|c|c|c|c|c|c|c|}
\hline Characteristics & $\begin{array}{l}\text { Negative* } \\
n=236\end{array}$ & $\begin{array}{l}\text { Campy } \\
n=13\end{array}$ & $\begin{array}{c}\text { ETEC } \\
n=25\end{array}$ & $\begin{array}{l}\text { Shigella } \\
n=4\end{array}$ & $\begin{array}{l}\text { Crypto } \\
n=14\end{array}$ & $\begin{array}{l}\text { Salmonella } \\
\quad n=5\end{array}$ & $\begin{array}{c}\text { Rotavirus } \\
n=38\end{array}$ & $\begin{array}{l}\text { Mixed }^{\dagger} \\
n=21\end{array}$ \\
\hline $\begin{array}{l}\text { Duration of diarrhoea since start, } \\
\text { in days, median }(I Q R)^{\ddagger}\end{array}$ & $5(3,7)$ & $4(3,7)$ & $4(3,7)$ & $8(6,12)$ & $7(3,10)$ & $7(4,7)$ & $4(3,7)$ & $3(3,5)$ \\
\hline $\begin{array}{l}\text { No. of loose/liquid stools during } \\
\text { last } 24 \mathrm{~h} \text {, median }(\mathrm{IQR})^{\ddagger}\end{array}$ & $8(6,10)$ & $7(6,8)$ & $6(6,10)$ & $10(8,10)$ & $10(5,10)$ & $9(8,9)$ & $8(6,10)$ & $8(6,12)$ \\
\hline $\begin{array}{l}\text { Maximum no. of loose/liquid } \\
\text { stools on any day, median }(I Q R)^{\ddagger}\end{array}$ & $8(6,10)$ & $7(6,8)$ & $7(6,10)$ & $9(7,11)$ & $10(6,10)$ & $10(6,10)$ & $10(6,11)$ & $10(6,12)$ \\
\hline Vomiting, $n(\%)$ & $115(49)$ & $6(46)$ & $13(52)$ & $1(25)$ & $8(57)$ & $2(40)$ & $29(76)$ & $12(57)$ \\
\hline $\begin{array}{l}\text { Maximum no. of vomiting } \\
\text { episodes on any day, median } \\
(I Q R)^{\ddagger}\end{array}$ & $4(2,5)$ & $5(4,7)$ & $4(2,6)$ & $4(3,4)$ & $5(4,5)$ & $4(3,4)$ & $6(4,6)$ & $5(4,5)$ \\
\hline Fever, $n(\%)$ & $160(68)$ & $6(46)$ & $17(68)$ & $3(75)$ & $11(79)$ & $4(80)$ & $34(89)$ & $18(86)$ \\
\hline Convulsions, $n(\%)$ & $6(3)$ & $2(15)$ & $1(4)$ & $0(0)$ & $0(0)$ & $0(0)$ & $2(5)$ & $0(0)$ \\
\hline Rectal prolapse, $n(\%)$ & $4(2)$ & $0(0)$ & $0(0)$ & $0(0)$ & $0(0)$ & $0(0)$ & $2(5)$ & $0(0)$ \\
\hline Mucus in stools, $n(\%)$ & $151(64)$ & $9(69)$ & $18(72)$ & $4(100)$ & $7(50)$ & $4(80)$ & $24(63)$ & $11(52)$ \\
\hline Blood in stools, $n(\%)$ & 40 (17) & $3(23)$ & $5(20)$ & $2(50)$ & $6(43)$ & $1(20)$ & $9(24)$ & $3(14)$ \\
\hline
\end{tabular}

Campy - Campylobacter, Crypto - Cryptosporidium, ETEC - enterotoxigenic Escherichia coli, IQR - interquartile range. *Negative cases or controls are episodes not associated with studied bacterial agents, rotavirus, or Cryptosporidium. ${ }^{\dagger}$ Any combination of at least two pathogens detected. ${ }^{\ddagger}$ Lower and upper quartiles.

Table VI. Actions taken for cases according to pathogen

\begin{tabular}{lcccccccc} 
Characteristics & $\begin{array}{c}\text { Negative* } \\
N=236\end{array}$ & $\begin{array}{c}\text { Campy } \\
N=13\end{array}$ & $\begin{array}{c}\text { ETEC } \\
n=25 \\
n(\%)\end{array}$ & $\begin{array}{c}\text { Shigella } \\
n=4\end{array}$ & $\begin{array}{c}\text { Crypto } \\
N=14\end{array}$ & $\begin{array}{c}\text { Salmonella } \\
N=5\end{array}$ & $\begin{array}{c}\text { Rotavirus } \\
N=38 \\
n(\%)\end{array}$ & $\begin{array}{c}\text { Mixed }^{+} \\
N=21 \\
n(\%)\end{array}$ \\
\hline $\begin{array}{l}\text { Children who } \\
\text { received ORS }\end{array}$ & $43(18)$ & $2(15)$ & $9(36)$ & $0(0)$ & $6(43)$ & $1(20)$ & $13(34)$ & $6(29)$ \\
\hline $\begin{array}{l}\text { Children who } \\
\text { received ORS } \\
\text { packets to take } \\
\text { at home }\end{array}$ & $184(78)$ & $11(85)$ & $23(92)$ & $3(75)$ & $13(93)$ & $3(60)$ & $35(92)$ & $16(76)$ \\
\hline $\begin{array}{l}\text { Children who } \\
\text { received medication }\end{array}$ & $199(84)$ & $11(85)$ & $20(80)$ & $4(100)$ & $12(86)$ & $3(60)$ & $34(89)$ & $15(71)$ \\
\hline $\begin{array}{l}\text { Children who } \\
\text { received IV fluids }\end{array}$ & $6(3)$ & $0(0)$ & $0(0)$ & $0(0)$ & $1(7)$ & $0(0)$ & $7(18)$ & $2(10)$ \\
\hline $\begin{array}{l}\text { Children admitted } \\
\text { to the hospital }\end{array}$ & $4(2)$ & $0(0)$ & $1(4)$ & $0(0)$ & $0(0)$ & $0(0)$ & $4(11)$ & $0(0)$
\end{tabular}

Campy - Campylobacter, Crypto - Cryptosporidium, ETEC - enterotoxigenic Escherichia coli, IV - intravenous, ORS - oral rehydration solution. *Negative cases or controls are episodes not associated with studied bacterial agents, rotavirus, or Cryptosporidium. ${ }^{\dagger}$ Any combination of at least two pathogens detected.

Cryptosporidium were identified in $13.2 \%$ and $3.9 \%$ of cases, respectively. Previous cohort studies in Egypt revealed that ETEC was the most frequent pathogen detected, with an incidence rate of 1.5 episodes/childyear, and that rotavirus-associated diarrhoea had an incidence rate of 0.24 episodes/child-year [3, 4]. Previous clinic-based studies showed that bacterial pathogens were identified in $25 \%$ of diarrhoea cases, whereas rotavirus and Cryptosporidium were detected in $21 \%$ and $15 \%$, respectively [8]. In our study, rotavirus was the pre- dominant pathogen recovered. This is consistent with other clinic-based surveillance for bacterial- and rotavirus-associated diarrhoea, where rotavirus was detected in $10 \%$ of cases of acute diarrhoea when excluding mixed rotavirus-bacterial infections in the Abu Homos district of Egypt [9]. Moreover, among patients with diarrhoea in the Eastern Mediterranean Region (EMR), rotavirus was detected in $40 \%$ of inpatients and in $23 \%$ of outpatients [10]. Relative to other regions in the world, the median rotavirus detection rate among hospitalised 
children with diarrhoea in the EMR (40\%) falls into the intermediate range between the higher level reported in Asia (45\%) and the lower rates found in Latin America (38\%) and Africa (24\%) [11, 12].

Similar to us, a community-based study identified rotavirus more often in the warmer months of the year [13]. Conversely, another report showed that rotavirus occurred more often during the cooler months, a pattern similar to that in other temperate climates [11] and similar to a report made from Bilbeis, Egypt [14]. Taken together, these studies suggest that rotavirus isa disease of the late warm and early cool seasons, but seasonality may vary year-to-year [9]. In 1986 Zaki et al. [14] reported that by 12 months of age, $66 \%$ of cases of rotavirus infection had occurred among Egyptian children. Reports from EMR indicated that $75 \%$ of rotavirus-associated diarrhoea occurred in children less than 3 years of age [10]. Male predominance was observed in a study from Saudi Arabia [15]; however, previous studies from Egypt observed lower male prevalence (52\%) among children attending clinics [9], and the incidence of rotavirus infection was lower in males in one of the cohort studies (0.21 episodes/child-year) [13].

Certain clinical features were suggestive of rotavirus-associated diarrhoea, including recurrent vomiting, urgent need for intravenous (IV) fluids, convulsions, and hospitalisation because of dehydration. Wierzba et al. [9] note drapid onset of symptoms, frequent watery stools, recurrent vomiting (87\%), dehydration (42\%), convulsions (1\%), and hospitalisation (45\%), all of which occurred more commonly with rotavirus than with other enteric pathogens.

Breastfeeding was associated with a reduced risk of rotavirus, ETEC, Campylobacter, Cryptosporidium, and culture-negative associated diarrhoea. It has been documented to be protective against many pathogens $[16,17]$, because of the presence of lactoferrin [16]. There is evidence that secretory immunoglobulin A antibodies in breast milk could protect against ETEC-associated diarrhoea in children. Nonetheless, some investigators report that breastfeeding did not appear to alter the risk of Campylobacter-associated diarrhoea.

Various reports from Egypt have identified a higher prevalence of ETEC, such as reports from Abu Homos (14\%), Benha (17\%) [9], and Aswan (17\%) [18]. This is in agreement with other hospital and community-based studies [14, 17, 19]. Enterotoxigenic E. coli among controls was insignificantly higher than among cases, in contrast to a study from Thailand [20], which reported that ETEC was isolated from $10 \%$ of cases with acute diarrhoea versus $6 \%$ of controls in Thai children aged 3 months to 5 years. Enterotoxigenic $E$. coli is an endemic disease in Egypt, and frequent infections may lead to natural immunity that protects against ETEC diarrhoea [21, 22]. Previous investigators [9, 17-19] found that ETEC-associated diarrhoea cases were more common during the warm seasons, just as we did. Also, the fact that the majority of cases of ETEC were detected by us in children younger than 2 years of age has been described by other researchers [23]. Wierzba et al. [9] revealed that cases with ETEC-associated diarrhoea were associated with fever (83\%), vomiting (67\%), dehydration (23\%), and convulsions (1\%). Mucus and blood in stools were present (63 and 1\%, respectively). No specific clinical features allowed ETEC to be differentiated from other bacterial pathogens causing diarrhoeal episodes, a finding that has also been seen in other community-based studies [24, 25].

In accordance with our data, Campylobacter, a poorly studied enteropathogen in the paediatric age group, was detected in children with acute diarrhoea in $1 \%$ and $3 \%$ of cases in Benha and Abu-Homos, respectively [9], while Mikhail et al. [18] and Abu Elamreen [26] noted higher figures (7\% and 5\%, respectively). We isolated Campylobacter from $3.1 \%$ of the controls, a finding similar to other researchers $[27,28]$. This may be due to natural immunity or an episode prior to the preceding 30 days. Campylobacter is endemic in the developing world, and infection is usually limited to children, suggesting that a high level of exposure in early life leads to the development of protective immunity $[27,28]$. As with the other pathogens, we found the incidence of diarrhoea decreased with age, consistent with other studies from developing areas, suggesting that there is an age-related acquisition of immunity [28-30]. The high percentage of convulsions found was also seen elsewhere, including possible febrile seizures [9, 31-33].

In developing countries Cryptosporidium is responsible for up to $20 \%$ of all cases of childhood diarrhoea [34]. Many studies in Egypt have described the importance of Cryptosporidium spp. as a causative agent of diarrhoea, especially among immunocompromised patients [35]. Mikhail et al. [18] recovered Cryptosporidium more frequently from in patients than from outpatients, suggesting that Cryptosporidium may be associated with severe diarrhoea. Our findings indicated that, as with other research projects [35, 36], warmer seasons and younger age were risk factors for developing Cryptosporidium-associated diarrhoea. Children $<12$ months of age were 2.4 times more likely to be infected with Cryptosporidium, and children 12 to 23 months of age were 1.9 times more likely to be infected with the organism compared to older children [34].

Two thirds of the cases were negative for studied pathogens. Likewise, Wierzba et al. [9] noted that negative cases constituted more than half of children with 
acute diarrhoea. These cases may be due to other viral infections such as astrovirus and norovirus, which are more prevalent in the first year of life and which may be responsible for more severe dehydration [13]. E. histolytica may also be responsible for many pathogen-negative cases. Three successive microscopic stool examinations should be done for detection of E. histolytica, Giardia lamblia, and Cryptosporidium. The combination of serological tests with detection of the parasite by antigen detection or polymerase chain reaction (PCR) offers the best approach to diagnosis, although PCR techniques remain impractical in many developing countries.

Some of the limitations of our study were related to problems in sample collection. Stool samples were collected from cases on the day of the visit only, so organisms necessitating another one or two samples in order to be detected, such as E. histolytica and G. lamblia, could not be definitely excluded. Also, rectal swabs from controls were not suitable to be tested for all studied pathogens because rotavirus and Cryptosporidium testing can only be performed on stool samples. Furthermore, other pathogens such as astrovirus, norovirus, Yersinia enterocolitica, Campylobacter concisus, and microsporidia were not tested for, in spite of their potential role in acute diarrhoea. Finally, the use of antibiotics prior to presentation may have had an impact on the isolation of bacterial pathogens.

\section{Conclusions}

In Egyptian children younger than 5 years of age, rotavirus is the most prevalent causative agent of acute diarrhoea. Laboratory confirmation of rotavirus is preferable. Oral rehydration solution is sufficient for symptomatic treatment of dehydration in most cases, and IV fluids are required only in selected complicated cases with dehydration. Expanded testing for additional viral, bacterial, and parasitic enteropathogens, including serological and molecular testing, are recommended to elaborate on "negative" cases and to help elucidate the distribution of enteropathogens among Egyptian children. Furthermore, stool samples should be collected from all controls, so that rotavirus and Cryptosporidium could be tested.

\section{Conflict of interest}

The authors declare no conflict of interest.

\section{References}

1. Boschi-Pinto C, Velebit L, Shibuya K. Estimating child mortality due to diarrhoea in developing countries. Bull World Health Organ 2008; 86: 710-17.

2. Vernacchio L, Vezina RM, Mitchell AA, et al. Diarrhea in American infants and young children in the community setting: in- cidence, clinical presentation and microbiology. Pediatr Infect Dis J 2006; 25: 2-7.

3. Mita AC, Denis LJ, Rowinsky EK, et al. Phase I and pharmacokinetic study of XRP6258 (RPR 116258A), a novel taxane, administered as a 1-hour infusion every 3 weeks in patients with advanced solid tumors. Clin Cancer Res 2009; 15: 723-30.

4. Svennerholm AM, Wiklund G. Rapid GM1-enzyme-linked immunosorbent assay with visual reading for identification of Escherichia coli heat-labile enterotoxin. J Clin Microbiol 1983; 17: 596-600.

5. Svennerholm AM, Wikstrom M, Lindblad M, et al. Monoclonal antibodies to Escherichia coli heat-labile enterotoxins: neutralising activity and differentiation of human and porcine LTs and cholera toxin. Med Biol 1986; 64: 23-30.

6. Viboud Gl, Binsztein N, Svennerholm AM. Characterization of monoclonal antibodies against putative colonization factors of enterotoxigenic Escherichia coli and their use in an epidemiological study. J Clin Microbiol 1993; 31: 558-64.

7. Gautam R, Lyde F, Esona MD, et al. Comparison of Premier ${ }^{\text {TM }}$ Rotaclone ${ }^{\circledR}$, ProSpec $T^{\mathrm{T} M}$, and RIDASCREEN $®$ rotavirus enzyme immunoassay kits for detection of rotavirus antigen in stool specimens. J Clin Virol 2013; 58: 292-4.

8. El-Mohamady H, Abdel-Messih IA, Youssef FG, et al. Enteric pathogens associated with diarrhea in children in Fayoum, Egypt. Diagn Microbiol Infect Dis 2006; 56: 1-5.

9. Wierzba TF, Abdel-Messih IA, Abu-Elyazeed R, et al. Clinic-based surveillance for bacterial- and rotavirus-associated diarrhea in Egyptian children. Am J Trop Med Hyg 2006; 74: 148-53.

10. Malek MA, Abu-Elyazeed R, Riddle MS, et al. The epidemiology of rotavirus diarrhea in countries in the Eastern Mediterranean Region. J Infect Dis 2010; 202 Suppl: S12-22.

11. Cunliffe NA, Kilgore PE, Bresee JS, et al. Epidemiology of rotavirus diarrhoea in Africa: a review to assess the need for rotavirus immunization. Bull World Health Organ 1998; 76: 525-37.

12. Bresee J, Fang ZY, Wang B, et al. First report from the Asian Rotavirus Surveillance Network. Emerg Infect Dis 2004; 10: 988-95.

13. Naficy AB, Abu-Elyazeed R, Holmes JL, et al. Epidemiology of rotavirus diarrhea in Egyptian children and implications for disease control. Am J Epidemiol 1999; 150: 770-7.

14. Zaki AM, DuPont HL, el Alamy MA, et al. The detection of enteropathogens in acute diarrhea in a family cohort population in rural Egypt. Am J Trop Med Hyg 1986; 35: 1013-22.

15. Tayeb HT, Balkhy HH, Aljuhani SM, et al. Increased prevalence of rotavirus among children associated gastroenteritis in Riyadh Saudi Arabia. Virol J 2011; 8: 548.

16. Ochoa TJ, Cleary TG. Effect of lactoferrin on enteric pathogens. Biochimie 2009; 91: 30-4.

17. Abu-Elyazeed R, Wierzba TF, Mourad AS, et al. Epidemiology of enterotoxigenic Escherichia coli diarrhea in a pediatric cohort in a periurban area of lower Egypt. J Infect Dis 1999; 179: 382-9.

18. Mikhail IA, Hyams KC, Podgore JK, et al. Microbiologic and clinical study of acute diarrhea in children in Aswan, Egypt. Scand J Infect Dis 1989; 21: 59-65.

19. Rao MR, Abu-Elyazeed R, Savarino SJ, et al. High disease burden of diarrhea due to enterotoxigenic Escherichia coli among 
rural Egyptian infants and young children. J Clin Microbiol 2003; 41: 4862-64.

20. Bodhidatta L, McDaniel P, Sornsakrin S, et al. Case-control study of diarrheal disease etiology in a remote rural area in Western Thailand. Am J Trop Med Hyg 2010; 83: 1106-9.

21. Svennerholm AM, Holmgren J, Sack DA. Development of oral vaccines against enterotoxinogenic Escherichia coli diarrhoea. Vaccine 1989; 7: 196-8.

22. Wenneras C, Svennerholm AM, Ahren C, et al. Antibody-secreting cells in human peripheral blood after oral immunization with an inactivated enterotoxigenic Escherichia coli vaccine. Infect Immun 1992; 60: 2605-11.

23. Hyams KC, Bourgeois AL, Merrell BR, et al. Diarrheal disease during operation desert shield. N Engl J Med 1991; 325: 1423-8.

24. Putnam SD, Riddle MS, Wierzba TF, et al. Antimicrobial susceptibility trends among Escherichia coli and Shigella spp. isolated from rural Egyptian paediatric populations with diarrhoea between 1995 and 2000. Clin Microbiol Infect 2004; 10: 804-10.

25. Clemens JD, Rao MR, Chakraborty J, et al. Breastfeeding and the risk of life-threatening enterotoxigenic Escherichia coli diarrhea in Bangladeshi infants and children. Pediatrics 1997; 100: e2.

26. Abu-Elamreen FH, Abed AA, Sharif FA. Viral, bacterial and parasitic etiology of pediatric diarrhea in Gaza, Palestine. Med Princ Pract 2008; 17: 296-301.

27. Blaser MJ. Epidemiologic and clinical features of Campylobacter jejuni infections. J Infect Dis 1997; 176 (Suppl. 2): S103-5.

28. Calva JJ, Ruiz-Palacios GM, Lopez-Vidal AB, et al. Cohort study of intestinal infection with campylobacter in Mexican children. Lancet 1988; 1: 503-6.

29. Taylor DN, Echeverria P, Pitarangsi C, et al. Influence of strain characteristics and immunity on the epidemiology of Campylobacter infections in Thailand. J Clin Microbiol 1988; 26: 863-8.

30. Taylor DN, Perlman DM, Echeverria PD, et al. Campylobacter immunity and quantitative excretion rates in Thai children. J Infect Dis 1993; 168: 754-8.

31. Rao MR, Naficy AB, Savarino SJ, et al. Pathogenicity and convalescent excretion of Campylobacter in rural Egyptian children. Am J Epidemiol 2001; 154: 166-73.

32. Solomon NH, Lavie S, Tenney BL, et al. Campylobacter enteritis presenting with convulsions. Clin Pediatr (Phila) 1982; 21: 118-9.

33. Lerner A, lanco TC, Landoy Z, et al. Seizures associated with Campylobacter jejuni enteritis. Pediatr Infect Dis 1984; 3: 281.

34. Mosier DA, Oberst RD. Cryptosporidiosis. A global challenge. Ann N Y Acad Sci 2000; 916: 102-11.

35. Hassanein SM, Abd-El-Latif MM, Hassanin OM, et al. Cryptosporidium gastroenteritis in Egyptian children with acute lymphoblastic leukemia: magnitude of the problem. Infection 2012; 40: 279-84.

36. Youssef FG, Adib I, Riddle MS, et al. A review of cryptosporidiosis in Egypt. J Egypt Soc Parasitol 2008; 38: 9-28.

Received: 4.10 .2014

Accepted: 7.12.2014 